\title{
Fonksiyonel derecelendirilmiş ortotropik bir kirişin statik ve titreşim davranışlarının incelenmesi
}

\author{
Şeref Doğuşcan AKBAŞ* \\ Bursa Teknik Üniversitesi, İnşaat Mühendisliği Bölümü, Yıldırım, Bursa. \\ Geliş Tarihi (Recived Date): 23.06.2017 \\ Kabul Tarihi (Accepted Date): 06.10.2017
}

\begin{abstract}
Özet
Bu çalışmada, fonksiyonel derecelendirilmiş konsol bir kirişin statik ve serbest titreşim davranışları ortotropik malzeme modeli kullanılarak incelenmiştir. Fonksiyonel derecelendirilmiş kirişin incelenmesinde düzlem parçalı sürekli ortam modeli kullanılmış olup, sonlu elemanlar yöntemi uygulanmıştır. Probleme ait yönetici denklemleri, virtüel yer değiştirmeler prensibi ile elde edilmiştir. Kirişin malzeme özellikleri, kiriş yüksekliği boyunca belli bir fonksiyona bağll olarak belirlenmiştir. Ele alınan kirişin boyutları, levha modeli olacak biçimde seçilerek düzlem gerilme problemi uygulanmıştır. Söz konusu problemin, sonlu elemanlar formülasyonları elde edilip, sonlu eleman çözümü için MATLAB programında algoritma ve program yazllarak sonuçlar elde edilmiştir. Ele alınan çalışmada, farklı malzeme dağılımlarının, kirişin statik ve titreşim davranışına olan etkileri incelenmiş̧tir. Değiş̧ik malzeme dağılımlarına göre, en büyük yer değiştirmeler ve doğal frekanslar elde edilip, yorumlanmuştır.
\end{abstract}

Anahtar kelimeler: Fonksiyonel derecelendirilmiş malzeme, düzlem gerilme problemi, sonlu elemanlar yöntemi, statik analiz, titreşim analizi.

\section{Investigation of static and vibration behaviors of a functionally graded orthotropic beam}

\begin{abstract}
In this paper, static and vibration behaviors of a functionally graded orthotropic beam are investigated. In the solution of the functionally graded beam, plane piecewise solid continua model and finite element method is used. The governing equations of the problems are obtained by using the virtual displacement principle. Material properties
\end{abstract}

\footnotetext{
*Şeref Doğuşcan AKBAŞ, serefda@yahoo.com, http://orcid.org/0000-0001-5327-3406
} 
of functionally graded beam vary across the height direction. With the dimensions of the functionally graded beam are assumed as plane model and the plane stress problem is implemented. In the solution of the finite element equations, MATLAB program is used. In the study, the effects of the different material distributions on the static and vibration behaviors of the beam are investigated. The maximum static deflections and natural frequencies are obtained and discussed for different material parameters.

Keywords: Functionally graded materials, plane stress problem, finite element method, static analysis, vibration analysis.

\section{Giriş}

Fonksiyonel derecelendirilmiş malzemeler, iki yada daha fazla farklı malzemelerin üstün özelliklerini birleştirerek daha dayanıklı bir malzeme oluşturulması amacıyla bir yapı içerisinde kademeli olarak değişmesiyle oluşturulan kompozit bir malzemedir. Fonksiyonel derecelendirilmiş malzemeler, 1984 yılında Japonya da bir uzay mekiği projesi sırasında, $10 \mathrm{~mm}$ den ince bir kesit için, $2000^{\circ} \mathrm{K}$ seviyesinde bir yüzey sıcaklığına ve $1000^{0} \mathrm{~K}$ 'lik bir sıcaklık aralığına dayanabilecek bir ısıl bariyer malzemesi önerisi ile ortaya çıkmıştır. 1984 ten bu yana, fonksiyonel derecelendirilmiş malzemeler çok geniş çapta araştırılmaktadır. Genellikle, yüksek sıcaklığa maruz yapısal elemanlarda kullanılan fonksiyonel derecelendirilmiş malzemeler, metal ve seramik karışımı türü malzemeler ile oluşmaktadır. Bilindiği gibi, metallerin yükssek sıcaklıkta dayanımları ciddi oranlarla düștüğünden dolayı seramik ile kaplanarak, yüksek sıcaklığa karşı korunmuş olurlar. Fakat oluşturulan bu tip termal bariyer yapılarda, farklı sicaklık genleşme katsayılardan dolayı, malzeme ara yüzeylerinde çatlak ve kırılmalar oluşmaktadır. Bu tür çatlak ve kırılmaları en aza indirgemek amacıyla, malzemeler kademeli olarak dağıtılarak, yapı içinde heterojen bir oluşum elde edilir. Ani süreksiz bölgeler yok edilerek, sıcaklık genleşme katsayıları arasındaki uyumsuzluklar en aza indirgenir ve bu bölgelerde oluşan ani kırılma ve çatlakların önlenmesini sağlanmış olur.

Son yıllarda fonksiyonel derecelendirilmiş yapılar ile ilgili yoğun çalışmalar yapılmaktadır. Fonksiyonel derecelendirilmiş kiriş ve levhaların statik ve titreşim davranışları ile ilgili çalışmalarda, belli bir çubuk, plak ve kabuk teorileri kullanılarak problemler ele alınmıştır. Fonksiyonel derecelendirilmiş kiriş ve levhalar ile ilgili çalışmalarda; Huang vd. [1] fonksiyonel derecelendirilmiş malzemelerin düzlem gerilme durumunda kırılma analizini çalışmışlardır. Ding vd. [2] fonksiyonel derecelendirilmiş anizotropik bir kirişin düzlem gerilme problemini analitik yöntemler ile incelemiştir. Huang vd. [3] anizotropik fonksiyonel derecelendirilmiş malzemelerin düzlem gerilme problemini manyetik etkiler için incelemiştir. Ke vd. [4] fonksiyonel derecelendirilmiş tabakalı yarı düzlemin sürtünmesiz kontak problemini araştırmışlardır. Zhang vd. [5] çatlak içeren fonksiyonel derecelendirilmiş sonsuz bir düzlemin düzlem olmayan kayma gerilmeleri altında davranışını incelemiştir. Lim vd. [6] fonksiyonel derecelendirilmiş dairesel kemerlerin sıcaklığa bağlı düzlemsel titreşimini iki boyutlu elastiste teorisi ile incelemiştir. Yang vd. [7], homojen malzeme ile bağlı fonksiyonel derecelendirilmiş bir tabakanın tahribatsız oyuk tespiti için bir yarı analitik yöntem önermişlerdir. Zhang vd. [8] çatlak içeren fonksiyonel derecelendirilmiş bir tabakanın dinamik düzlem problemini incelemişledir. Kocatürk ve Akbaş $[9,10]$ ile Akbaş ve Kocatürk [11] fonksiyonel derecelendirilmiş kirişlerin termal burkulma 
sonrası davranışlarını incelemişleridir. Pan vd. [12] fonksiyonel derecelendirilmiş piezoelektrik ve piezomanyetik bir levhanın Schmidt yöntemi kullanarak kırılma analizini yapmışlardır. Kubair [13] dairesel boşluk içeren radyal yönde derecelendirilmiş bir panelin gerilme yığılması faktörlerini ile gerilme değişimlerini araştırmıştır. Akbaş [14-17] kenar çatlaklı fonksiyonel derecelendirilmiş kirişlerin dinamik ve geometrik doğrusal olmayan analizlerini incelemiştir. $\mathrm{Li}$ ve $\mathrm{Hu}$ [18] fonksiyonel derecelendirilmiş malzemeden yapılmış basit çerçevelerin geometrik doğrusal olmayan analizini yapmışlardır. Daouadji vd. [19] fonksiyonel derecelendirilmiş konsol bir kirişin düzlem gerilme problemini elastisite teorisi ile çözmüştür. Alibeigloo ve Liew [20] fonksiyonel derecelendirilmiş silindirik sandviç bir panelin serbest titreşimini üç boyutlu elastisite teorisi ile çözmüştür. Çömez [21] fonksiyonel derecelendirilmiş iki tabakalı bir kirişin analitik çözümünü yapmıştır. Liu vd. [22] fonksiyonel derecelendirilmiş malzeme ile kaplı yarı bir düzlemin dinamik stabilitesini incelemişleridir. Akbaş [23] eksenel olarak fonksiyonel derecelendirilmiş üç boyutlu kirişlerin burkulma sonrası analizini araştırmıştır. Yue vd. [24] fonksiyonel derecelendirilmiş elasto-manyetik konsol bir kirişin düzlem problem ile analitik olarak incelemiştir. Son yıllarda fonksiyonel derecelendirilmiş malzemelerin mekanik davranışları ile ilgili bir çok çalışma literatürde yer almıştır [25-41].

$\mathrm{Bu}$ çalışmada fonksiyonel derecelendirilmiş malzemeden yapılmış ortotropik bir konsol kirişin yayılı yükleme altında statik ile serbest titreşim davranışları incelenmiştir. Kiriş elemanı, levha olarak modellenmiş olup, düzlem parçalı sürekli ortam modeli kullanılmıştır. Probleme ait yönetici denklemleri, virtüel yer değiştirmeler prensibi ile elde edilmiş olup, problemin çözümünde sonlu elemanlar yöntemi kullanılmıştır. Farklı malzeme dağılımlarına göre statik ve titreşim davranışları elde edilmiş ve yorumlanmıştır.

\section{Teori ve formülasyon}

Düzgün yayılı yük etkisi altında $(q)$, fonksiyonel derecelendirilmiş malzemeden yapılmış ortotrop konsol bir kiriş, $X, Y, Z$ koordinat takımı ile birlikte şekil 1'de gösterilmiştir. Kirişin yatay ve düşey uzunlukları sırasıyla $L_{x}, L_{y}$, kalınlığ 1 ise $t_{z}$ ile gösterilmiştir.

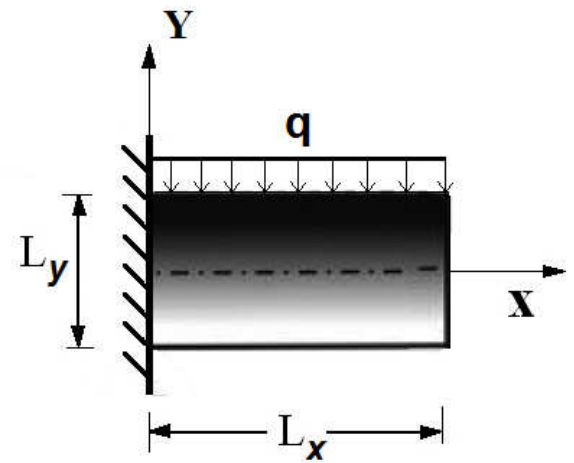

a) Yan Görünüş

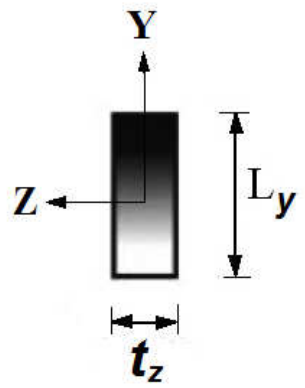

b) Enkesit

Şekil 1. Düzgün yayılı yük etkisi altında, fonksiyonel derecelendirilmiş konsol bir kiriş.

a) Yan görünüş, b) Enkesit. 
Malzeme dağılımı şekil 1 de görüldüğ̈̈ üzere kiriş yüksekliği boyunca belli bir derecelendirmeye bağlı olarak değişmektedir. Bu çalışmada malzeme dağılımı, kiriş kalınlığı boyunca üstel bir fonksiyona bağlı olarak değişmektedir:

$$
P(Y)=P_{0} e^{\beta Y}
$$

Burada $P$ malzeme özelliklerini (Elastisite Modülü, Poisson oranı, yoğunluk vb.) göstermektedir. $P_{0}$ kirişin orta yüzeyinin malzeme özellikleri, $\beta$ ise fonksiyonel derecelendirme katsayısını göstermektedir. Eşitlik (1), $Y=-h / 2$ olduğunda alt malzeme özelliklerini ve $Y=h / 2$ olduğunda üst malzeme özelliklerini verir. Ayrıca, $\beta=0$ olması durumunda, Eşitlik (1) e göre kiriş malzemesi homojen olmaktadır.

Ele alınan problem, düzlem parçalı sürekli ortam modeli ve sonlu elemanlar yöntemi kullanılarak çözülmüştür.

Düzlem elastisite problemi için hareket denklemleri izleyen şekilde verilmiştir:

$\frac{\partial \sigma_{X X}}{\partial X}+\frac{\partial \sigma_{X Y}}{\partial Y}+k_{X}=\rho(Y) \frac{\partial^{2} u}{\partial t^{2}}$

$\frac{\partial \sigma_{X Y}}{\partial X}+\frac{\partial \sigma_{Y Y}}{\partial Y}+k_{Y}=\rho(Y) \frac{\partial^{2} v}{\partial t^{2}}$

Burada $\sigma_{X X}, \sigma_{Y Y}$ sirasıyla $X$ ve $Y$ doğrultularındaki normal gerilmeler, $\sigma_{X Y}$ ise kayma gerilmesini göstermektedir. $k_{X}$ ve $k_{Y}$ sırasıyla $X$ ve $Y$ doğrultularındaki birim hacmin kütle kuvvetleridir. $\rho(Y)$ kütle yoğunluğu olup, fonksiyonel derecelendirilmiş malzeme olması durumunda, eşitlik (1) e göre $Y$ doğrultusunda derecelendirilmiştir. $u$ ve $v$ sırasıyla yatay ve düş̧ey yer değiştirmeleri, $t$ ise zamanı göstermektedir.

Probleme ait şekil değiştirme- yer değiştirme ilişkisi izleyen şekilde verilmiştir:

$\varepsilon_{X X}=\frac{\partial u}{\partial X}, \quad \varepsilon_{Y Y}=\frac{\partial v}{\partial Y}, 2 \varepsilon_{X Y}=\frac{\partial u}{\partial Y}+\frac{\partial v}{\partial X}$

Burada $\varepsilon_{X X}, \varepsilon_{Y Y}$ sırasıyla $X$ ve $Y$ doğrultularındaki eksenel şekil değiştirmeleri, $\varepsilon_{X Y}$ ise açısal şekil değiştirmeyi göstermektedir. Şekil değiştirme ile yer değiştirme arasındaki bağıntı, matris formda aşağıdaki gibi yazılır:

$\left\{\begin{array}{c}\varepsilon_{X X} \\ \varepsilon_{Y Y} \\ 2 \varepsilon_{X Y}\end{array}\right\}=\left[\begin{array}{cc}\frac{\partial}{\partial X} & 0 \\ 0 & \frac{\partial}{\partial Y} \\ \frac{\partial}{\partial Y} & \frac{\partial}{\partial X}\end{array}\right]\left\{\begin{array}{l}u \\ v\end{array}\right\}$

$\{\varepsilon\}=[D]\{d\}$

Burada $[D]$ Şekil değiştirme ile yer değiştirmeler arasındaki diferansiyel operatör, $\{d\}$ ise yer değiștirme vektörüdür.

Probleme ait bünye denklemleri izleyen şekilde verilmiştir. 


$$
\begin{aligned}
& \left\{\begin{array}{l}
\sigma_{X X} \\
\sigma_{Y Y} \\
\sigma_{X Y}
\end{array}\right\}=\left[\begin{array}{ccc}
C_{11}(Y) & C_{12}(Y) & 0 \\
C_{12}(Y) & C_{22}(Y) & 0 \\
0 & 0 & C_{66}(Y)
\end{array}\right]\left\{\begin{array}{c}
\varepsilon_{X X} \\
\varepsilon_{Y Y} \\
2 \varepsilon_{X Y}
\end{array}\right\} \\
& \{\sigma\}=[C]\{\varepsilon\}
\end{aligned}
$$

Burada $[C]$ ortotropik malzeme için indirgenmiş bünye tansörü, $C_{11}, C_{12}, C_{22}, C_{66}$ fonksiyonel derecelendirilmiş ile ortotropik malzeme için indirgenmiş bünye tansör birleşenleri olup, değerleri düzlem gerilme hali için izleyen ifadelerde verilmiştir:

$$
\begin{aligned}
& C_{11}(Y)=\frac{E_{11}(Y)}{1-v_{12}(Y) v_{21}(Y)}, \quad C_{22}(Y)=\frac{E_{22}(Y)}{1-v_{12}(Y) v_{21}(Y)} \\
& C_{12}(Y)=v_{21}(Y) C_{11}(Y)=v_{12}(Y) C_{22}(Y), \quad C_{66}(Y)=G_{12}(Y)
\end{aligned}
$$

Burada $E_{11}, X$ doğrultusundaki Elastisite modülü, $E_{22}, Y$ doğrultusundaki Elastisite modülü, $v_{12}$ ile $v_{21} X, Y$ doğrultuları için Poisson oranı, $G_{12} X Y$ düzlemindeki kayma modülüdür. Bünye tansör birleşenleri, $Y$ koordinatının bir fonksiyonu olup, eşitlik (1) e göre derecelenmektedir.

Probleme ait yönetici denklemlerinin elde edilmesinde virtüel yer değiștirmeler prensibinden yaralanmıştır. Dinamik etkileri göz önüne alınarak, düzlem parçalı sürekli ortam modeli için virtüel iş izleyen şekilde verilmiştir:

$$
\begin{aligned}
& t_{z} \int_{A}\left(\sigma_{X X} \delta \varepsilon_{X X}+2 \sigma_{X Y} \delta \varepsilon_{X Y}+\sigma_{Y Y} \delta \varepsilon_{Y Y}+\rho(Y) \ddot{u} \delta u+\rho(Y) \ddot{v} \delta v\right) d A \\
& -t_{z} \int_{S}\left(r_{X} \delta u+r_{Y} \delta v\right) d S-t_{z} \int_{A}\left(k_{X} \delta u+k_{Y} \delta v\right) d A=0
\end{aligned}
$$

Burada $r_{X}$ ve $r_{Y}$ yüzey kuvvetleridir. (7) eşitliğindeki $\ddot{u}, \ddot{v}$ ifadeleri, zamana göre ikinci türevi göstermektedir. Probleme ait sonlu elemanlar çözümü için, 12 düğüm noktalı dikdörtgen sonlu eleman kullanılmıştır (Şekil 2).

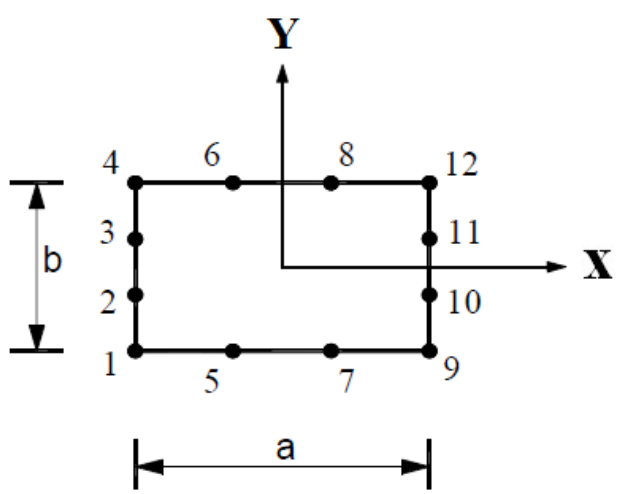

Şekil 2. 12 dügü̈m noktalı dikdörtgen, iki boyutlu eleman. 
Şekil 2 de $a$ ve $b$ sırasıyla sonlu elemanın yatay ve düşey uzunluklarını göstermektedir. Sonlu elemanın yer değiştirme alanları düğüm yer değiştirmeleri cinsinden izleyen şekilde ifade edilir:

$$
\begin{aligned}
& \{d\}=[\varnothing]\left\{d_{n}\right\} \\
& u=\left(u_{1} \emptyset_{1}+u_{2} \emptyset_{2}+u_{3} \emptyset_{3}+u_{4} \emptyset_{4}+u_{5} \emptyset_{5}+u_{6} \emptyset_{6}+u_{7} \emptyset_{7}+u_{8} \emptyset_{8}+u_{9} \emptyset_{9}\right. \\
& \left.+u_{10} \emptyset_{10}+u_{11} \emptyset_{11}+u_{12} \emptyset_{12}\right) \\
& v=\left(v_{1} \emptyset_{1}+v_{2} \emptyset_{2}+v_{3} \emptyset_{3}+v_{4} \emptyset_{4}+v_{5} \emptyset_{5}+v_{6} \emptyset_{6}+v_{7} \emptyset_{7}+v_{8} \emptyset_{8}+v_{9} \emptyset_{9}\right. \\
& \left.+v_{10} \varnothing_{10}+v_{11} \emptyset_{11}+v_{12} \emptyset_{12}\right)
\end{aligned}
$$

Burada $\left\{d_{n}\right\}$ dügüm noktalarına ait yer değiştirme vektörü olup, birleşenleri $u_{i}$ ve $v_{i}$ dir. Eşitlik (8)'de $\emptyset_{i}$ şekil fonksiyonlarını göstermektedir. 12 dügüm noktalı dikdörtgen sonlu elemana ait şekil fonksiyonları izleyen şekilde ifade verilmiştir:

$$
\begin{aligned}
& \emptyset_{1}=\frac{1}{32}\left(1-\frac{2 X}{a}\right)\left(1-\frac{2 Y}{b}\right)\left(-10+9\left(\frac{4 X^{2}}{a^{2}}+\frac{4 Y^{2}}{b^{2}}\right)\right), \quad \emptyset_{2}=\frac{9}{32}\left(1-\frac{2 X}{a}\right)\left(1-\frac{4 Y^{2}}{b^{2}}\right)\left(1-\frac{6 Y}{b}\right) \\
& \emptyset_{3}=\frac{9}{32}\left(1-\frac{2 X}{a}\right)\left(1-\frac{4 Y^{2}}{b^{2}}\right)\left(1+\frac{6 Y}{b}\right), \quad \emptyset_{4}=\frac{1}{32}\left(1-\frac{2 X}{a}\right)\left(1+\frac{2 Y}{b}\right)\left(-10+9\left(\frac{4 X^{2}}{a^{2}}+\frac{4 Y^{2}}{b^{2}}\right)\right) \\
& \emptyset_{5}=\frac{9}{32}\left(1-\frac{2 Y}{b}\right)\left(1-\frac{4 X^{2}}{a^{2}}\right)\left(1-\frac{6 X}{a}\right), \quad \emptyset_{6}=\frac{9}{32}\left(1+\frac{2 Y}{b}\right)\left(1-\frac{4 X^{2}}{a^{2}}\right)\left(1-\frac{6 X}{a}\right) \\
& \emptyset_{7}=\frac{9}{32}\left(1-\frac{2 Y}{b}\right)\left(1-\frac{4 X^{2}}{a^{2}}\right)\left(1+\frac{6 X}{a}\right), \quad \emptyset_{8}=\frac{9}{32}\left(1+\frac{2 Y}{b}\right)\left(1-\frac{4 X^{2}}{a^{2}}\right)\left(1+\frac{6 X}{a}\right) \\
& \emptyset_{9}=\frac{1}{32}\left(1+\frac{2 X}{a}\right)\left(1-\frac{2 Y}{b}\right)\left(-10+9\left(\frac{4 X^{2}}{a^{2}}+\frac{4 Y^{2}}{b^{2}}\right)\right), \quad \emptyset_{10}=\frac{9}{32}\left(1+\frac{2 X}{a}\right)\left(1-\frac{4 Y^{2}}{b^{2}}\right)\left(1-\frac{6 Y}{b}\right) \\
& \emptyset_{11}=\frac{9}{32}\left(1+\frac{2 X}{a}\right)\left(1-\frac{4 Y^{2}}{b^{2}}\right)\left(1+\frac{6 Y}{b}\right), \quad \emptyset_{12}=\frac{1}{32}\left(1+\frac{2 X}{a}\right)\left(1+\frac{2 Y}{b}\right)\left(-10+9\left(\frac{4 X^{2}}{a^{2}}+\frac{4 Y^{2}}{b^{2}}\right)\right)
\end{aligned}
$$

(4) ile (8) eşitlikleri, (5) eşitliğinde yerlerine yazılırsa bünye bağıntısı izleyen şekilde olur:

$$
\{\sigma\}=[C][D][\varnothing]\left\{d_{n}\right\}=[C][B]\left\{d_{n}\right\}
$$

(10) eşitliğinde $[B]$ ifadesi, $[B]=[D][\emptyset]$ olarak tanımlanmıştır. Virtüel yer değiştirme ile şekil değiştirmelerin matris formları izleyen şekilde verilmiştir:

$$
\{\delta d\}=[\varnothing]\left\{\delta d_{n}\right\}, \quad\{\delta \ddot{d}\}=[\varnothing]\left\{\delta \ddot{d}_{n}\right\}, \quad\{\delta \varepsilon\}=[B]\{\delta d\}
$$

(10) ve (11) eşitlikleri virtüel iş eşitliğine yerine yazıldığında, izleyen ifade elde edilir:

$$
\begin{aligned}
& t_{z} \int_{A}\left\{\delta d_{n}\right\}^{T}\left([B]^{T}[C][B]\left\{d_{n}\right\}+\rho(Y)[\varnothing]^{T}[\varnothing]\{\delta \ddot{d}\}\right) d A-t_{z} \int_{S}\left\{\delta d_{n}\right\}^{T}[\varnothing]^{T}\left\{\begin{array}{l}
r_{X} \\
r_{Y}
\end{array}\right\} d S \\
& -t_{z} \int_{A}\left\{\delta d_{n}\right\}^{T}[\varnothing]^{T}\left\{\begin{array}{l}
k_{X} \\
k_{Y}
\end{array}\right\} d A=0
\end{aligned}
$$


$\left\{\delta d_{n}\right\}^{T}\left([K]\left\{d_{n}\right\}+[M]\{\ddot{d}\}-\{r\}-\{s\}\right)=0$

(12) gerekli düzenlemeler yapıldıktan sonra, probleme ait sonlu elemanlar hareket denklemi izleyen şekilde olur:

$[K]\left\{d_{n}\right\}+[M]\{\ddot{d}\}=\{F\}$

Burada $[K]$ rijitlik matrisi, $[M]$ kütle matrisi, $\{F\}$ yük vektörü, $\left\{d_{n}\right\}$ yer değiştirme vektörü, $\{\ddot{d}\}$ ivme vektörü, $\{s\}$ düğüm noktalarına indirgenmiş kütle kuvvetleri vektörü, $\{r\}$ düğüm noktalarına indirgenmiş dış yükler vektörüdür. Sonlu elemanlar hareket denklemini oluşturan birleşenler izleyen şekilde ifade edilmiştir:

$$
\begin{aligned}
& {[K]=t_{z} \int_{A}[B]^{T}[C][B] d A} \\
& {[M]=t_{z} \int_{A} \rho(Y)[\varnothing]^{T}[\varnothing] d A} \\
& \{F\}=\{r\}+\{s\} \\
& \{r\}=\int_{S}[\varnothing]^{T}\left\{\begin{array}{l}
r_{X} \\
r_{Y}
\end{array}\right\} d S \\
& \{s\}=\int_{A}[\varnothing]^{T}\left\{\begin{array}{l}
k_{X} \\
k_{Y}
\end{array}\right\} d A
\end{aligned}
$$

(13) eşitliğinde verilen eleman rijitlik matrisi, kütle matrisi ve yük vektörü, bilinen sonlu elemanlar birleștirme işlemleri sonucu sistem rijitlik matrisi, kütle matrisi ve yük vektörü elde edilir. Bu matris ve vektörlerin boyutları, sistemin serbestlik derecesi kadar olur.

Statik çözüm için, yönetici ve hareket denklemlerinde yer alan zaman ile zamanın türevi ifadeler sıfır alınarak elde edilen denklemler kullanılır:

$$
[K]\left\{d_{n}\right\}=\{F\}
$$

Serbest titreşim problemi için ise, (13) eşitliğin sağ tarafındaki yük vektörü sıfır alınarak elde edilen denklem ile çözüme ulaşılır. Bu durumda elde edilen denklem ile özdeğer problemi oluşmaktadır:

$[K]\left\{d_{n}\right\}+[M]\{\ddot{d}\}=0$

$\left([K]-w^{2}[M]\right)\left\{\hat{d}_{n}\right\}=0$

Burada $w$ sistemin doğal açısal frekansı, $\left\{\hat{d}_{n}\right\}$ ise mod vektörüdür.

Elde edilen sonlu elemanlar denklemlerinin integrasyon hesaplarında, beş noktalı Gauss integral Kuralı kullanılmıştır. Sonlu elemanlar denklemlerinin çözümü, sayısal ve grafik sonuçların elde edilmesinde, MATLAB programında algoritma ve program yazılmıştır. 


\section{Sayısal analiz}

Sayısal analizde, farklı malzeme dağılımlarına göre, fonksiyonel derecelendirilmiş konsol kirişin statik ve serbest titreşim davranışları elde edilmiş ve incelenmiştir. Kiriş malzemesi olarak, ortotrop özelliği olan epoksi cam malzemesi düşünülmüştür. Eşitlik (1) de verilen göre fonksiyonel derecelendirilmiş malzeme modeline göre, Epoksi cam malzemesi kirişin orta yüzeyinde tamamen kendi özelliğinde olup, diğer yüzeylere derecelendirme katsayısına göre ağırlıkça derecelendirilmiştir. Epoksi cam'ın malzeme özellikleri; $E_{11}=48.3 \mathrm{GPa}, E_{22}=19.8 \mathrm{GPa}, G_{12}=8.96 \mathrm{GPa}, v=0.27, \rho=1.8 \mathrm{~g} / \mathrm{cm}^{3}$ [25]. İncelenen problemde, kiriş boyutları levha gibi seçilmişsir; $L_{X}=5 \mathrm{~m}, L_{Y}=5 \mathrm{~m}, t_{Z}=30 \mathrm{~cm}$.

Sonlu elemanlar formülasyonlarının çözümünde, geometrik sınır koşulları olarak, kirişin sol tarafı ankastre mesnetli olduğundan dolayı, yer değiştirme vektörünün mesnet noktalarına karşılık gelen değerleri sıfır alınır:

$u_{1}=u_{2}=u_{3}=u_{4}=v_{1}=v_{2}=v_{3}=v_{4}=0, \quad \mathrm{X}=0, \quad-0.5 L_{Y} \leq \mathrm{Y} \leq 0.5 L_{Y}$

Sayısal hesaplamalarda sonlu eleman sayısını belirleyebilmek için öncelikle hem statik hem de serbest titreşim davranışları üzerine yakınsama çalışması yapılmıştır. Şekil 3'de fonksiyonel derecelendirme katsayısı $\beta=0.2$ için fonksiyonel derecelendirilmiş konsol kirişin en büyük statik düşey yer değiştirmesi ile doğal frekansları, değişik sonlu eleman sayılarına göre hesaplanmış ve gösterilmiştir. Şekil 3'deki statik en büyük düşey yer değiştirme grafiğinde, yayılı yük $q=600000 \mathrm{kN} / \mathrm{m}$ alınmıştır. Şekil 3'deki yakınsama grafiklerinde, yatay sonlu eleman $m$, düşey sonlu eleman $n$ ile gösterilmiştir. Ele alınan problemdeki kirişin yatay ve düşey boyutları eşit olduğu için, sonlu eleman sayısı belirlerken yatay ve düşey sonlu elemanlar eşit alınmıştır $(m=n)$.
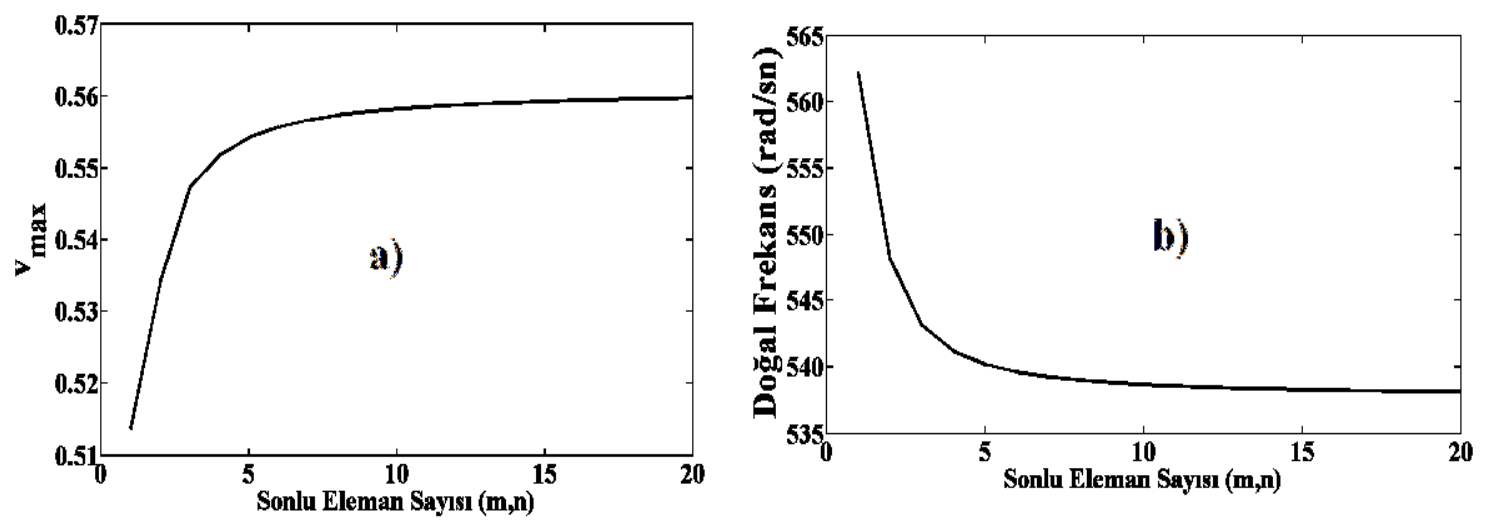

Şekil 3. Sonlu eleman sayısı için yakınsama çalışması. a) statik durum için (en büyük düşey yer değiştirme $v_{\max }$ ) b) serbest titreşim durumu için (doğal frekans).

Şekil 3'de görülmektedir ki, hem yatay hem de düşey sonlu eleman sayıları (m,n) 12 değerine ulaştıktan sonra, statik ve titreşim sonuç eğrileri yakınsamaktadır. Yakınsama çalışması neticesinde, sayısal hesaplarda sonlu eleman sayıları $m=n=12$ alınmıştır.

Şekil 4 ve 5 de farklı malzeme dağılımlarının, yani farklı fonksiyonel derecelendirme katsayısının ( $\beta$ ) kirişin maksimum statik düş̧ey yer değiştirmesine olan etkisi gösterilmiştir. Şekil 5'deki hesaplarda farklı $(\beta)$ değerlerinin etkisini daha görünür elde etmek için yayılı yük $q=1200000 \mathrm{kN} / \mathrm{m}$ alınmıştır. Şekil 4 ve 5 'den görüldüğü üzere, 
derecelendirme katsayısı $(\beta)$ değeri arttıkça yer değiştirmeler ciddi biçimde azalmaktadir.

Çünkü fonksiyonel derecelendirme katsayısı artıkça kiriş malzemesinin Elastisite modülü eşitlik (1) e göre artmakta, dolaysıyla kirişin rijitliği artmaktadır. Bu düşüş formu şekil 5 de daha açıkça görülmektedir. Şekil 5 de, fonksiyonel derecelendirme katsayısı $\beta=1.5 \sim 2$ arası değerlerinden sonra, yer değiştirmeler yataya asimptot olup, sıfıra yaklaşmaktadır. Bu sonuçlardan görülmektedir ki, malzeme dağılımı seçiminin, yapı elemanının mekanik davranışı üzerinde çok önemli bir etkisi vardır.

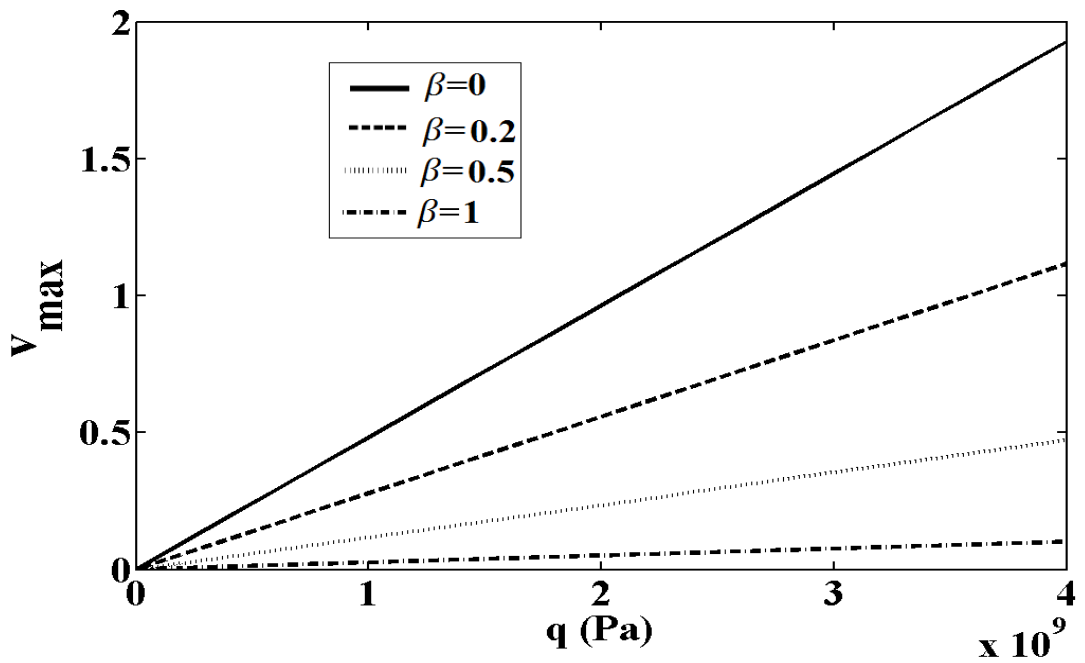

Şekil 4. Farklı derecelendirme katsayısına göre, yük-maksimum düşey yer değiştirme ilişkisi.

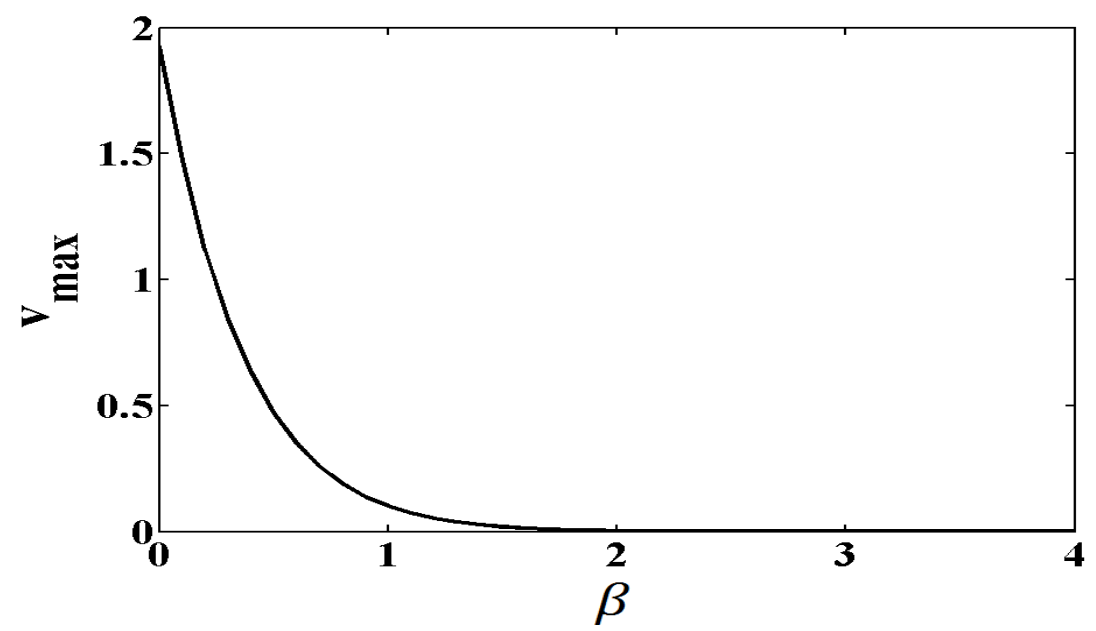

Şekil 5. Fonksiyonel derecelendirme katsayısı ile maksimum düşey yer değiştirme arasındaki ilişki ( $q=1200000 \mathrm{kN} / \mathrm{m}$ için).

Fonksiyonel derecelendirme katsayısının, statik yer değiştirmeler üzerindeki etkisini daha net görebilmek amacıyla, farklı $\beta$ değerlerine göre kirișin yer değiștirmiş konumları şekil 6'da gösterilmiştir. Buradaki şekil değiştirmiş konumlar ve diğer şekiller, MATLAB' da algoritma ve program yazılarak elde edilmiştir. Şekil 6'da, kirişin konumları sonlu eleman üzerinde gösterilmiştir. Şekil 6'da, $\beta$ değerinin statik yer değiştirmeler üzerinde önemli etkisi olduğu daha net görülmektedir. Küçük $\beta$ 
değerlerinde, yer değiştirmeler oldukça büyüktür. $\beta$ değerlerinin artmasıyla birlikte, yapı elemanı daha da dayanıklı olmaktadır.

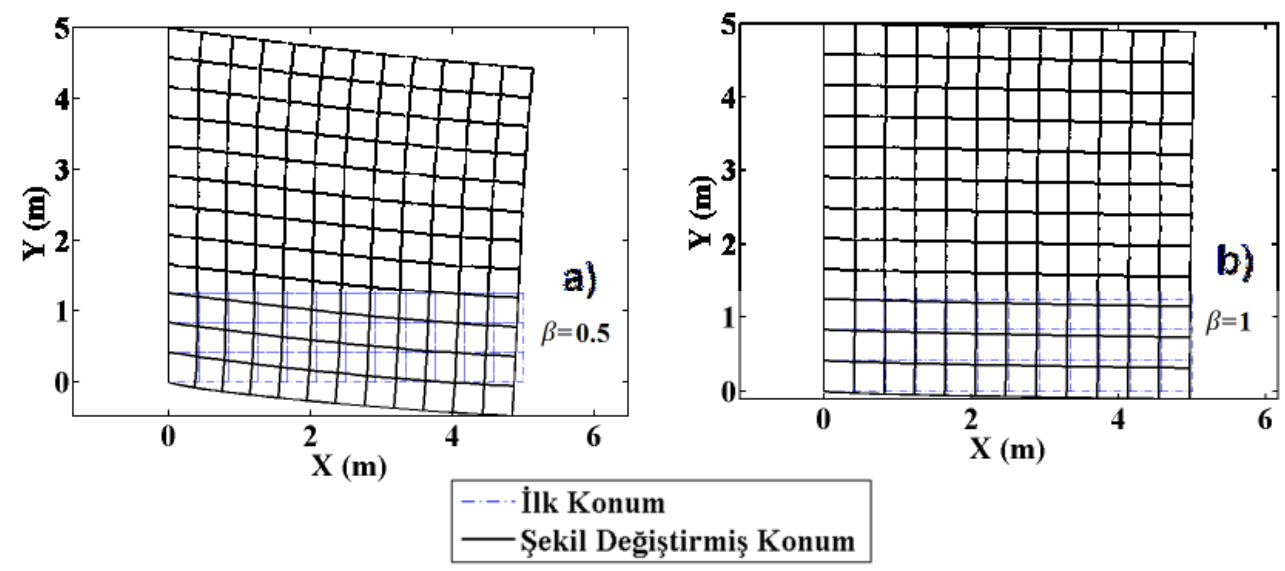

Şekil 6. Farklı fonksiyonel derecelendirme katsayılarına göre ile kirişin yer değiştirmiş konumları (q=1200000 kN/m için). a) $\beta=0.5$, b) $\beta=1$.

Şekil 7'de farklı fonksiyonel derecelendirme katsayısının kirişin doğal açısal frekansına olan etkisi gösterilmiştir. Şekil 7'den görüldüğü üzere, $\beta$ değeri arttıkça frekanslar ciddi biçimde düşmekte ve belli bir $\beta$ değeri sonrasında sabit bir değere doğru yaklaşmaktadır. Farklı malzeme dağılımı, kirişin titreşim özelliklerini oldukça değiştirmektedir. Buradan görülmektedir ki, fonksiyonel derecelendirilmiş bir yapının tasarımında, en uygun derecelendirme katsayısının seçimi oldukça önemlidir.

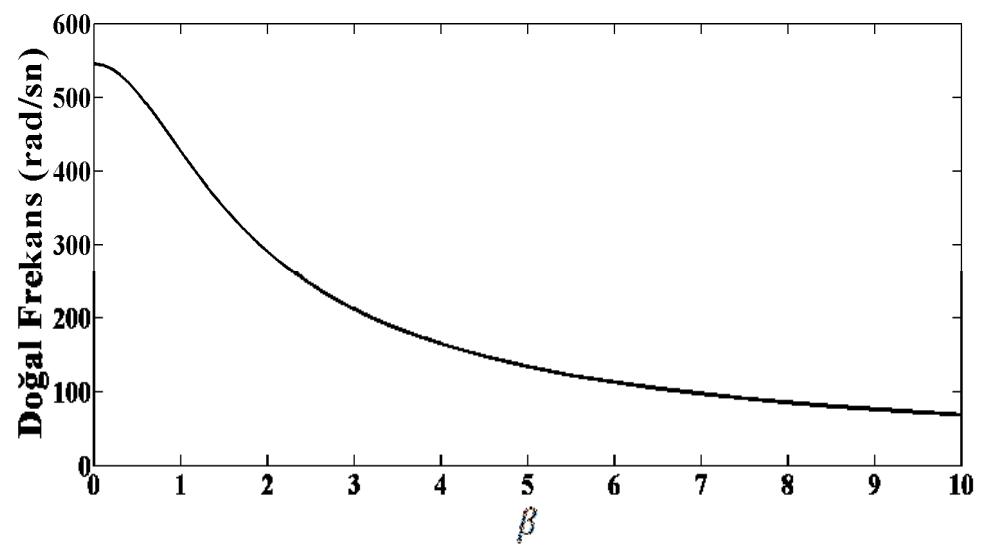

Şekil 7. Fonksiyonel derecelendirme katsayısı ile doğal açısal frekanslar arasındaki ilişki

Şekil 8 ve 9'da, farklı $\beta$ değerlerine göre kirişin 1. ve 2. mod şekilleri verilmiştir. Şekil 8 ve 9'da, farklı malzeme dağılımlarının kirişin titreşim davranışına olan etkisi mod şekilleri üzerinden net etkili olduğu görülmektedir. 

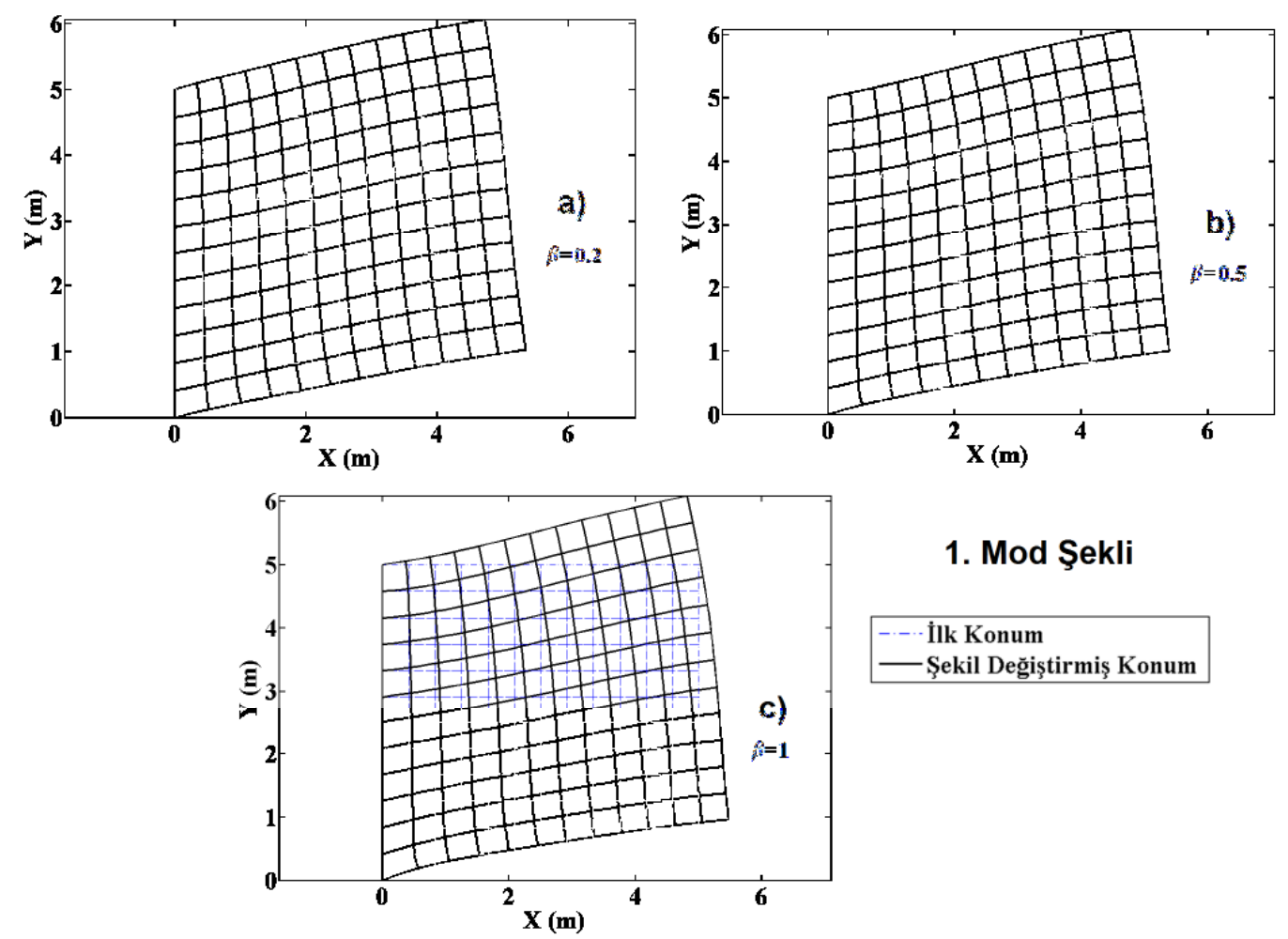

1. Mod Şekli

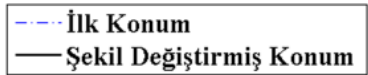

Şekil 8. Farklı fonksiyonel derecelendirme katsayılarına göre ile kirişin 1. mod şekli. a) $\beta=0.2$, b) $\beta=0.5$, c) $\beta=1$.
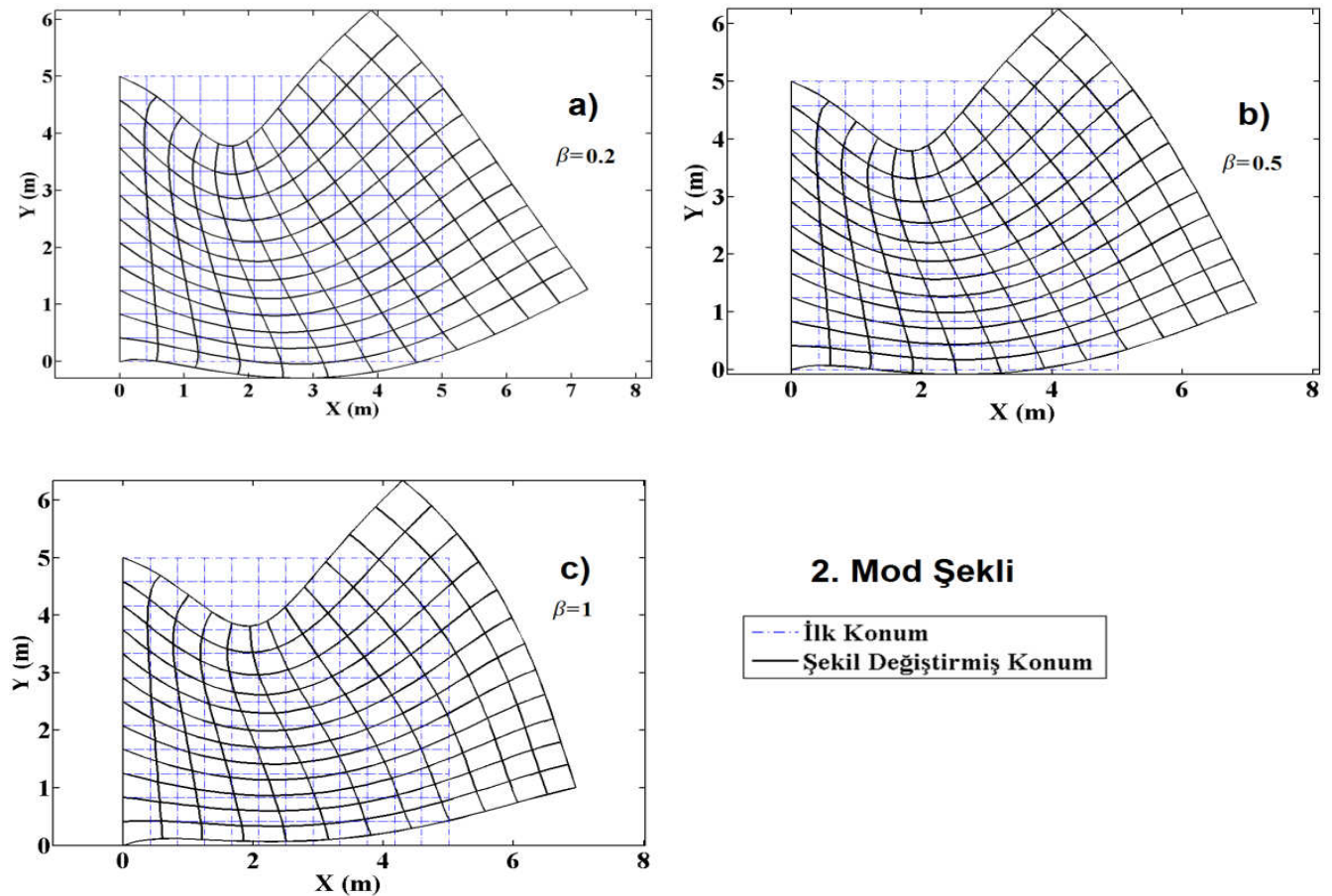

\section{Mod Şekli}

\begin{tabular}{l}
\hline Illk Konum \\
- Şekil Değiştirmiş Konum
\end{tabular}

Şekil 9. Farklı fonksiyonel derecelendirme katsayılarına göre ile kirişin 2. mod şekli. a) $\beta=0.2$, b) $\beta=0.5$, c) $\beta=1$. 


\section{Sonuçlar}

Ele alınan çalışmada, fonksiyonel derecelendirilmiş ortotropik konsol bir kirişin statik ve serbest titreşim davranışları düzlem parçalı sürekli ortam modeli ile sonlu elemanlar yöntemi kullanılarak incelenmiştir. Kirişin malzeme özellikleri, kiriş yüksekliği boyunca belli bir düzene göre dağılmıştır. Problemin sayısal çözümlemeleri için MATLAB programında algoritma ve program yazılmıştır. Farklı malzeme dağılımlarının, kirişin statik ve titreşim davranışına olan etkileri incelenmiştir.

Elde edilen sonuçlardan da görülmektedir ki, fonksiyonel derecelendirme katsayısının kirişin statik ve titreşim davranışları üzerinde önemli bir etkisi olduğu, kirişin rijitliğini önemli derecede etkilediği görülmüştür. Fonksiyonel derecelendirilmiş bir yapının tasarımında, en uygun derecelendirme katsayısının seçimi, böylesi malzemeler için oldukça önemlidir.

\section{Kaynaklar}

[1] Huang, G.-Y., Wang, Y.-S. and Yu, S.-Y, A new model for fracture analysis of functionally graded coatings under plane deformation, Mechanics of materials, 37, 507-516, (2005).

[2] Ding, H.J., Huang, D.J. and Chen, W.Q., Elasticity solutions for plane anisotropic functionally graded beams, International Journal of Solids and Structures, 44, 176-196, (2007).

[3] Huang, D.J., Ding, H.J. and Chen, W.Q, Analytical solution for functionally graded magneto-electro-elastic plane beams, International Journal of Engineering Science, 45, 467-485, (2007).

[4] Ke, L.L., Yang, J., Kitipornchai, S. and Wang, Y.S., Frictionless contact analysis of a functionally graded piezoelectric layered half-plane, Smart Materials and Structures, 17, 025003, (2008).

[5] Zhang, P.W., Zhou, Z.G. and Wu., L.Z., Behaviour of three parallel nonsymmetric mode III cracks in a functionally graded material plane, Proceedings of the Institution of Mechanical Engineers, Part C: Journal of Mechanical Engineering Science, 222, 2311-2330, (2008).

[6] Lim, C.W., Qian Y. and Lü., C.F. Two-dimensional elasticity solutions for temperature-dependent in-plane vibration of FGM circular arches, Composite Structures, 90, 323-329, (2009).

[7] Yang, Y.-H., Wu, L.-Z. and Fang., X.-Q, Non-destructive detection of a circular cavity in a finite functionally graded material layer using anti-plane shear waves, Journal of Nondestructive Evaluation, 29, 233-240, (2010).

[8] Zhang, H.Z., Zhao, X. H., Zhang, J.Z. and Zhou, Z.G., Random dynamic response of crack in functionally graded materials layer for plane problem, Transactions of Nonferrous Metals Society of China, 22, 198-206, (2012).

[9] Kocatürk, T. and Akbaş, Ş.D., Post-buckling analysis of Timoshenko beams made of functionally graded material under thermal loading, Structural Engineering and Mechanics, 41, 775-789, (2012).

[10] Kocatürk, T. and Akbaş Ş.D., Thermal post-buckling analysis of functionally graded beams with temperature-dependent physical properties, Steel and Composite Structures, 15, 481-505, (2013). 
[11] Akbaş, Ş.D. and Kocatürk, T., Post-buckling analysis of functionally graded three-dimensional beams under the influence of temperature, Journal of Thermal Stresses, 36, 1233-1254, (2013).

[12] Pan, S.-D, Zhou, Z.-G. and Wu, L.-Z, Basic solutions of multiple parallel symmetric mode-III cracks in functionally graded piezoelectric/piezomagnetic material plane, Applied Mathematics and Mechanics, 34,1201-1224, (2013).

[13] Kubair, D.V., Stress concentration factors and stress-gradients due to circular holes in radially functionally graded panels subjected to anti-plane shear loading, Acta Mechanica, 224, 2845-2862, (2013).

[14] Akbaş, Ş.D., Free vibration characteristics of edge cracked functionally graded beams by using finite element method, International Journal of Engineering Trends and Technology, 4, 4590-4597, (2013).

[15] Akbaş, Ş.D., Geometrically nonlinear static analysis of edge cracked Timoshenko beams composed of functionally graded material, Mathematical Problems in Engineering, 2013, (2013).

[16] Akbaş, Ş.D., On Post-Buckling Behavior of Edge Cracked Functionally Graded Beams Under Axial Loads, International Journal of Structural Stability and Dynamics, 15, 1450065, (2015).

[17] Akbaş, Ş.D. Wave propagation in edge cracked functionally graded beams under impact force, Journal of Vibration and Control, 22, 2443-2457, (2016).

[18] Li, S. and Hu, Y., Geometrically Nonlinear Analysis of Simple Plane Frames of Functionally Graded Materials, Sixth International Conference on Nonlinear Mechanics (ICNM-6). DEStech Publications, Inc, (2013).

[19] Daouadji, T.H., Henni, A.H., Tounsi, A. and El Abbes, A.B., Elasticity solution of a cantilever functionally graded beam, Applied Composite Materials, 20, 115, (2013).

[20] Alibeigloo, A. and Liew, K.M., Free vibration analysis of sandwich cylindrical panel with functionally graded core using three-dimensional theory of elasticity, Composite Structures, 113, 23-30, (2014).

[21] Çömez, I., Elasticity solution for a functionally graded two-layer beam with simple supported edges, Turkish Journal of Engineering and Environmental Sciences, 38, 373-381, (2016).

[22] Liu, J., Wang, Y.S., Ke, L.L., Yang, J. and Alam, F., Dynamic instability of an elastic solid sliding against a functionally graded material coated half-plane, International Journal of Mechanical Sciences, 89, 323-331, (2014).

[23] Akbaş, Ş.D., Post-buckling analysis of axially functionally graded threedimensional beams, International Journal of Applied Mechanics, 7, 1550047, (2015).

[24] Yue, Y., Xiaofen Y. and Kaiyu X., Analytical solutions for plane problem of functionally graded magnetoelectric cantilever beam, Applied Mathematics and Mechanics, 36, 955-970, (2015).

[25] Yuan, F.G. and Hsieh, C.C., Three-dimensional wave propagation in composite cylindrical shells, Composite Structures, 42, 153-167, (1998).

[26] Akgöz, B. and Civalek, O., Bending analysis of FG microbeams resting on Winklerelastic foundation via strain gradient elasticity, Composite Structures, 134, 294-301, (2015).

[27] Akbaş, Ş.D.. Static analysis of a functionally graded beam with edge cracks on elastic foundation. In: Proceedings of the 9 th International Fracture Conference, Istanbul, Turkey, pp. 70-80, (2011). 
[28] Akbaş, Ş.D., Free vibration of edge cracked functionally graded microscale beams based on the modified couple stress theory, International Journal of Structural Stability and Dynamics, 17, 1750033, (2017).

[29] Akbaş, Ş.D., Free vibration and bending of functionally graded beams resting on elastic foundation, Research on Engineering Structures and Materials, 1, (2015).

[30] Akgoz, B. and Civalek, O., Bending analysis of embedded carbon nanotubes resting on an elastic foundation using strain gradient theory, Acta Astronautica, 119, 1-12, (2016).

[31] Akbaş, Ş.D., Free vibration of axially functionally graded beams in thermal environment, International Journal of Engineering and Applied Sciences, 6, 37-51, (2014).

[32] Akbaş, Ş.D., Vibration and Static Analysis of Functionally Graded Porous Plates, Journal of Applied and Computational Mechanics, 3, 199-207, (2017).

[33] Akbaş, Ş.D., Kirişlerin Geometrik Doğrusal Olmayan Davranışlarının 3 Boyutlu Sürekli Ortam Modeli ile İncelenmesi, Balıkesir Üniversitesi Fen Bilimleri Enstitüsü Dergisi, 17, 28-37, (2016).

[34] Akbaş, Ş.D., Stability of A Non-Homogenous Porous Plate by Using Generalized Differantial Quadrature Method, International Journal of Engineering and Applied Sciences, 9, 147-155, (2017).

[35] Akbaş, Ş.D., Post-buckling analysis of edge cracked columns under axial compression loads, International Journal of Applied Mechanics, 8, 1650086, (2016).

[36] Civalek, O. and Demir C.A., simple mathematical model of microtubules surroundedby an elastic matrix by nonlocal finite element method, Applied Mathematicsand Computation, 289, 335-352, (2016).

[37] Akbaş, Ş.D., Thermal Effects on the Vibration of Functionally Graded Deep Beams with Porosity, International Journal of Applied Mechanics, 9, 1750076, (2017).

[38] Akbaş, Ş.D., Post-buckling responses of functionally graded beams with porosities, Steel and Composite Structures, 24, 481-579-589, (2017).

[39] Ansari, R., Gholami, R. and Sahmani, S., Size-dependent vibration of functionallygraded curved microbeams based on the modified strain gradient elasticity theory. Archive of Applied Mechanics, 83, 1439-1449, (2013).

[40] Kocatürk, T. and Akbas, Ş.D., Geometrically non-linear static analysis of a simply supported beam made of hyperelastic material, Structural Engineering and Mechanics, 35, 677-697, (2010).

[41] Eltaher, M.A., Khater, M.E. and Emam, S.A., A review on nonlocal elastic models for bending, buckling, vibrations, and wave propagation of nanoscale beams, Applied Mathematical Modelling, 40, 4109-4128, (2016). 